\title{
The Moderating Effects of Basic Needs Satisfaction at Work on the Relationships Between Burnout, Work-Family Conflict and Organizational Commitment: Relevance of the Conservation of Resources (COR) Theory
}

\author{
Suzalina Mohd Shuhaimi \\ Najib Ahmad Marzuki \\ School of Social Development, College of Arts and Sciences, Universiti Utara Malaysia \\ suzalinashuhaimi09@gmail.com/najib320@uum.edu.my
}

\section{Doi:10.5901/mjss.2015.v6n4s3p506}

\section{Abstract}

In this modern era of competitiveness, work commitment is imperative as every organization strive to excel. Employees must find the means to achieve goals with full determination and commitment despite their personal difficulties. This paper analyses the moderation effect of the dimensions of basic needs satisfaction at work (autonomy, relatedness, and competence) on the relationships between burnout (exhaustion, professional efficacy, and cynicism), work-family conflict (work interfering with family (WIF), family interfering with work (FIW)), and the dimensions of organizational commitment (affective, continuance and normative). Two hundred and twenty administrative and professional groups from Kuala Lumpur City Hall (KLCH), Malaysia were involved in the study. The data gathered was examined using hierarchical multiple regression analysis to determine the moderating effects between variables. The findings revealed that: (1) autonomy moderates the relationships between exhaustion and continuance commitment; and (2) relatedness moderates the relationships between WIF and continuance commitment. The study has defined the motivating factors using the Conservation of Resources (COR) theory as a foundation for the discussion. Recommendations and areas for future research are also discussed.

Keywords: basic needs satisfaction; organizational commitment; burnout; work-family conflict.

\section{Introduction}

Basic needs satisfaction at work is known as a vital predictor of optimal individual functioning in various life domains (Broeck, Vansteenkiste, Witte, Soenens, \& Lens, 2010). According to Ryan and Deci (2004), basic needs satisfaction at work is defined as the integration between innate psychological needs and support from the social environment. It is important to understand such work-related needs as they contribute to job outcomes. These needs have an effect on both individuals' feelings and the end results of work (Silman, 2014).

The concept of basic psychological needs has been postulated by self-determination theory, which emphasises intrinsic needs rather than extrinsic needs such as obtaining rewards. It presents the basis for describing the environment's characteristics in the attempt to adapt or oppose new situations (Ryan \& Deci, 2004). It also reflects the human behaviour on the effects of social contexts or environment where by it eased the self-motivation (Ryan \& Deci, 2004; Hodgins \& Knee, 2004) and well-being (Ryan \& Deci, 2004; Molix \& Nichols, 2013). Specifically, the theory proposes three needs that should be satisfied by a supportive environment to enhance optimal growth. These needs comprise of: (1) the need for autonomy (the sense of self-expression, initiative, and value); (2) competence (the sense of effectiveness, confidence, and capacity in action); and (3) relatedness (the sense of connection and belonging) (Deci \& Ryan, 2000; Ryan \& Deci, 2004). It is understood that basic needs satisfaction at work occurs in a work environment where employees are able to fulfil their needs and thus contribute to the benefit of the organization.

This study has focused on civil servant issues. The importance of addressing basic needs satisfaction in this setting is due to the recent directive by the Malaysian Government calling for the civil sector to become globally competitive. The improvement of service delivery in terms of quality and quantity is required as stated in the Government Transformation Programme (GTP). These challenges require civil servants to improve productivity and performance in accordance with public needs, expectations, and feedback (Muhyiddin, 2010).

The new policy requires the civil servant to work quite diligently towards new goals. The need to enhance the intrinsic motivator is vital, as public sector employees tend to value intrinsic motivators more compared to private sector employees (Perry \& Wise, 1990; Brehm \& Gates, 1997; Frank \& Lewis, 2003). Regardless, a motivated employee is much needed in the new setting, since a motivated employee will be more committed and dedicated to his work (Gagne \& 
Deci, 2005; Harris \& Hagger, 2007).

Although the public has high expectations for the improved public service, employees may perceive the situation as a new stressor. The consequences of excessive work, continuous pressure, and job demands are very likely to lead to burnout (Ishak, 2004). Apart from that, another area that has a big impact on employee productivity and performance is balance between work and family matters. Employees will be more productive when work-family balance is achieved (Aamodt, 2010).

Understanding of basic needs satisfaction at work is essential, as there is a lack of information on this topic. More research should be conducted to examine the contribution of each respective work need in predicting various results. Hence, it is vital to examine the causal relations between basic needs satisfaction at work with its antecedents and consequences in order to understand more about work and psychological needs (Broeck, Vansteenkiste, Witte, Soenens, \& Lens, 2010; Sheldon \& Bettencourt, 2002; Silman, 2014).

The expansion of the needs concept is important in order to understand recent lifestyle. The concept has not been fully expanded, even though its function is as equally important as physiological needs (Ryan \& Deci, 2004). In addition, research on the impact of basic psychological needs is required at both the applied contextual and situational levels (Harris \& Hagger, 2007; Jawahar, Stone, \& Kismore, 2007; Vallerand \& Ratelle, 2004; Lam \& Gland, 2008).

This study has also focused on the relevance of Conservation of Resources Theory (COR theory) in the determination and observation of resources by measuring behaviour and structural design. The use of COR theory is not merely to integrate discussion on the understanding of certain behaviour, or to acknowledge the existence of potential resources (Hobfoll, 1989). COR theory was chosen because it was found that existing theories failed to integrate with other theories in terms of explanation of certain situations, and that those theories could not be used to refine current knowledge into a central framework (Gorgierski \& Hobfoll, 2008; Grandey \& Cropanzano, 1999; Neubert \& Wu, 2009).

Thus, this study concentrated on the measures of basic needs satisfaction at work as the moderating factor in order to understand the role of an intrinsic motivation in impacting the relationships between burnout and work-family conflict on organizational commitment. The findings for these relationships have been justified through the application of COR theory.

\subsection{Conservation of Resources Theory (COR)}

COR theory (Hobfoll, 1989; 2011) is a theory that rests on the basic principle that individuals strive to minimize the net loss of their resources. Consequently, their actions focus on obtaining, maintaining, fostering, and protecting resources to avoid a state of actual or potential loss of valuable resources. Resources are defined as entities that have intrinsic or extrinsic value, including objects (e.g. car, house, tools for work), conditions (e.g. parental role, tenure, seniority at work, good marriage), personal resources (e.g. self-esteem, self-efficacy and occupational skills), and energy resources (e.g. money, knowledge and time).

Attempts to hold on to resources as well as psychological stress occur in one of the three following conditions: (1) when resources are threatened; (2) when resources are lost; and (3) when individuals invest resources and do not obtain the expected level of return (Hobfoll \& Freedy, 1993; Hobfoll, 2001). In the face of potential or actual loss of resources, the feeling of lost resources occurs, while resource gain occurs when individuals are not currently facing any threats to resources. People strive to develop a surplus of resources to offset the potential of future demand and restored gains.

Therefore, in order to address the theoretical gap of this study, COR theory was used as an underlying framework in determining the links between work and non-work roles and their relationships with stress (McPadden, 2006). COR theory also helps in achieving primary perception and understanding of some phenomenon, thus promoting theoretical construction and providing a valuable framework that allows for the immediate study of process and outcome (Hobfoll \& Freedy, 1993). Using COR theory as a guide provides a means for predicting and understanding work-life conflict and behavioural outcome (Grandey \& Cropanzano, 1999), as well as providing a framework for certain variables that may act as a resource, thereby facilitating the emergence of personal and social resources (i.e. organizational commitment) of COR theory (Wright, 2004).

This paper discusses two objectives of the study:

i. To determine which type of basic needs satisfaction (autonomy, competence and relatedness) moderates the relationship between burnout (exhaustion, professional efficacy, and cynicism) and organizational commitment (affective, continuance, and normative).

ii. To determine which type of basic needs satisfaction (autonomy, competence, or relatedness) moderates the relationship between work-family conflict (WIF and FIW) and organizational commitment (affective, continuance, and normative). 


\section{Literature Review}

\subsection{Burnout}

Burnout is defined as a drain of emotional or mental resources caused by persistent job stress and is measured by workrelated psychological health (Schaufeli, van Dierendonck, \& van Gorp, 1996). In other words, burnout occurs as the effect of stress due to excessive work. Those who face continuous pressures and demands at work may be susceptible to risk of burnout (Schultz \& Schultz, 2014; Ishak, 2004). According to Maslach (1982), burnout was indicated through emotional exhaustion (depletion of emotional resources), depersonalization (detached attitude), and personal accomplishment (feelings about job productivity and competence).

Findings from past research have shown that high quality relationships with co-workers and work motivation of need satisfaction are negatively associated with emotional exhaustion (Broeck, Vansteenkiste, Witte, \& Lens, 2008; Fernet, Gagne, \& Austin, 2010) and depersonalization but positively related with personal accomplishment (Fernet et al., 2010). This means that those who possess desirable job attributes are more likely to experience psychological satisfaction at work, rather than those who are dealing with excess job demands and who are vulnerable to burnout.

Burnout has been found to have a significant relationship with organizational commitment (Wright, 2004; Gemlik, Sisman, \& Sigri, 2010), as those who have high emotional exhaustion tend to have low affective and normative commitment. However, those who have low levels of personal accomplishment may experience an increase in continuance commitment. This is due to their length of service in the same organization, which in turn lowers their selftrust in their work. However, this situation brings up the continuance commitment to maintain the status quo (Gemlik et al., 2010). The level of work could also cause burnout due to the addition of responsibilities, as found in Jackson, Turner, and Brief (1987), where those who were responsible at a supervisory level were reported to experience having a higher level of burnout. A study by Najihah, Norsyamina, Mizan, and Jeniwaty (2011) also found that individuals who have a high degree of commitment towards their organizations experience a greater amount of stress than those who are less committed.

\subsection{Work-family conflict}

According to Schultz and Schultz (2014), work-family conflict is a clash in attaining balance between work needs and the need to fulfil family pursuits. Work-family conflict is also known as a form of inter-role conflict where there is conflict in performing different functions and incompatibility between the domains of work and family (Greenhaus \& Beutell, 1985). There can be, however, motivation factors arising from the social context - for example, the interpersonal behaviour of a spouse at home or an employer at work may reduce work-family conflict (Senecal, Vallerand, \& Guay, 2001). Nevertheless, these findings were contradicted by a study by Maqsood, Muhammad, and Saleem (2012) in which the social context of perceived supervisor support did not moderate the relationships between perceived supervisor support and job satisfaction.

Apart from that, work-family conflict may ruin the efficiency of an organization, as it can cause shortfalls in productivity as well as increased absenteeism (Aamodt, 2010). Another consequence of a high work-family conflict rate is a low level of organizational commitment (Siegel, Post, Fishman, Brockner, \& Garden, 2005; Akintayo, 2010). This indicates that work-family conflict has a big impact on the workplace performance of employees with regards to factors that motivate them to turn up at work and be responsible for their conduct.

\subsection{Organizational commitment}

Organizational commitment is defined as the degree of psychological attachment to an organization, consisting of: (1) the acceptance of the organization's values and goals; (2) willingness to work for the organization; and (3) a strong inclination to be with the organization (Schultz \& Schultz, 2014). In addition, Meyer and Allen (1991) defined organizational commitment as affective (psychological attachment), continuance (cost to leave), and normativeness (obligation to stay).

The importance of intrinsic motivation on the impact of organizational commitment has been discussed thoroughly, and studies have found that intrinsic motivation is significantly correlated to organizational commitment (Choong, Wong, \& Lau, 2011; Marescaux, Winne, \& Sels, 2011). The study also found that intrinsic motivators in an organization are important components in promoting commitment towards the organization, while intrinsic work motivation has a positive influence on organizational and personal resources with basic psychological needs satisfaction being positively related to affective organizational commitment (Salanova, Bakker, \& Llorens, 2006). 


\subsection{Basic needs satisfaction as a moderating factor}

Basic needs satisfaction has been used to understand the force of motivation, for example, in a study by Harris and Hagger (2007), which analysed the moderation effect between subjective norms and intentions for restrictive dietary behaviours. Other antecedent research has used various motivation factors, such as in Fernet, Guay, and Seneccal (2004), who examined self-determination in work motivation as the moderating effect between job demand, job control and burnout. Job resources were used as the moderator between job demand and burnout (Faisal, Rosman, \& Anwar, 2014) and work motivation as the moderating factor between quality relationships and burnout. Research has identified that work motivation (job resources) plays a role as a motivator (Fernet, Gagne, \& Austin, 2010).

Thus, an organization has to invest more in intrinsic motivation, as suggested by Gagne and Deci (2005), as employees who are motivated will be connected to work, responsible, able to balance the amount of work, keen to take challenges, and inspired to develop professionally. It was also found that those who are satisfied with their work and are high achievers are more dedicated to their work.

Since previous studies have mostly focused on the relationship of burnout and work-family conflicts with the basic needs satisfaction as mediator or moderating factor between other variables, there is a need to further explore basic needs satisfaction as a moderating factor in the relationships between burnout, work-family conflict and organizational commitment. This study therefore hypothesized that:

Hypothesis 1(H1): Basic needs satisfaction (11. autonomy, 12. competence and 13. relatedness) will moderate the relationships between burnout (1a. exhaustion, 1b. professional efficacy and 1c. cynicism) and organizational commitment (1i. affective, 1ii. continuance and 1iii. normative).

Hypothesis 2(H2): Basic needs satisfaction (21. autonomy, 22. competence and 23. relatedness) will moderate the relationships between work-family conflict (2a.WIF and 2b.FIW) and organizational commitment (2i.affective, 2ii.continuance and 2iii.normative).

\subsection{Conceptual framework}

The conceptual framework of the study indicates the moderating effects of the basic needs satisfaction dimensions on the burnout, work-family conflict and organizational commitment dimensions. The analysis was conducted based on the framework in order to demonstrate the impact of basic needs satisfaction on organizational commitment with regards to the issues of burnout and work-family conflict.

Figure 1 illustrates the relationship between the independent and dependent variables of the study.

INDEPENDENT VARLABLE

DEPENDENT VARLABLE

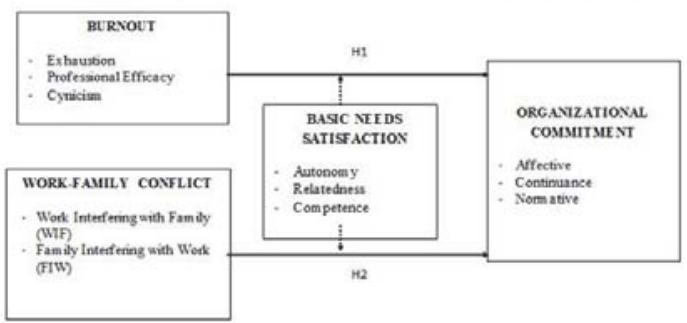

Figure 1. Research framework between burnout, work-family conflict, basic needs satisfaction, and organizational commitment

\section{Method}

\subsection{Sample and procedure}

Participants of the study were administrators and professionals at Kuala Lumpur City Hall (KLCH), Malaysia. A set of questionnaires was distributed to 300 officers and 220 completed the survey, with a response rate of 73 percent. Sample selection was executed by applying stratified random sampling where participants were categorized according to departments and field duties from the records of available position listings. The selection process began with a random selection from stratum based on the important features examined in this study. The selection of the sample size was determined using Krejcie and Morgan (1970) sample determination table, with 220 found to be the acceptable number for this study. 


\subsection{Instruments}

Burnout: The questionnaire used in this study was taken from the Maslach Burnout Index-General Survey (MBI-GS) (Maslach, Jackson, Leiter, Schaufeli, \& Schwab, 1986). This is a 16-item instrument on a seven-point Likert scale ranging from (0) never to (6) every day, measuring five items for exhaustion, six items for professional efficacy, and five items for cynicism.

Work-family Conflict: Work-family conflict was measured with the 18 item Work-Family Conflict Scale (Carlson, Karmac, \& Williams, 2000). It measures the two directions of work-family conflict with nine items on work interfering with family (WIF) and another nine items on family interfering with work (FIW). The scale was a seven-point Likert scale ranging from (1) strongly disagree to (5) strongly agree.

Basic Needs Satisfaction at Work: The original measure of the Basic Needs Satisfaction at Work Scale (Deci, Ryan, Gagne, Leone, Usunov, \& Kornazheva, 2001) was used in this study. The instrument consists of 21 items with seven scales ranging from (1) not at all true to (7) very true. The scale measures seven items for autonomy, six items for competence and eight items for relatedness. Nine items are negatively worded, requiring reverse scoring.

Organizational Commitment: Organizational commitment was measured with the Organizational Commitment Scale (Meyer \& Allen, 1991), which is a 18-item Likert scale. It consists of three dimensions reflecting the psychological state of the employees, to assess affective, normative and continuance commitment. The seven-point scale's response categories range from (1) strongly disagree to (7) strongly agree. Four items are worded negatively requiring reverse scoring in order to compute the scale scores.

\subsection{Data analysis}

The hypotheses were tested using hierarchical multiple regression analyses. For the first hypothesis, the burnout dimensions (i. exhaustion, ii. professional efficacy and iii. cynicism) were entered in step 1, basic needs satisfaction (i. autonomy, ii. relatedness and iii. competence) in step 2 and the interaction terms involving burnout dimensions with each dimension of basic needs satisfaction in step 3. The repetition of the process for affective, continuance and normative commitment was separately structured, as the analysis's objectives focused on the effect on each of the organizational commitment dimensions. The interaction terms were centred and multiplied together between each of the dimensions of the independent variables (i.e. burnout and work-family conflict) with the dimensions of moderating variables (basic needs satisfaction).

The same process was applied for the second hypothesis where the work-family conflict dimensions were entered in step 1, basic needs satisfaction (autonomy, relatedness, and competence) in step 2, and the interaction terms between work-family conflict dimensions with each element of basic needs satisfaction in step 3. The tests for affective, continuance, and normative commitment were analysed accordingly.

\section{Results}

The analysis on the moderation effect of autonomy, relatedness and competence of basic needs satisfaction on the relationships between each of the dimensions of burnout (exhaustion, professional efficacy and cynicism) and organizational commitment (affective, continuance and normative) is shown in Table 1. Based on the table, the analysis for the affective commitment column found that all of the interaction terms in step 3 between burnout dimensions and basic needs satisfaction dimensions (Ex/Pe/Cy x Au, Ex/Pe/Cy x Re and Ex/Pe/Cy x Co) were not significant. This indicates that autonomy, relatedness and competence of basic needs satisfaction did not moderate the relationship between burnout dimensions and affective commitment.

The statistical results for the normative commitment aspect of organizational commitment found in the final model indicate that the added interaction terms were significant, with $R^{2}=.095, F(7,212)=3.2, p<.05, R^{2}=.106, F(7,212)=3.57$, $p<.05$ and $R^{2}=.078, F(7,212)=2.56, p<.05$. However, all of the interaction terms were not significant, and this indicates that autonomy, relatedness, and competence of basic needs satisfaction did not moderate the relationships between exhaustion, professional efficacy, and cynicism of burnout with normative commitment.

The results for the effect of continuance commitment in the organizational commitment column showed that there was a $9.4 \%$ variance of continuance commitment $F(7,212)=3.1, p<.05$ for the final model, after the addition of interaction terms with autonomy effect. Nevertheless, the only sign of significance was found in the interaction term between exhaustion and autonomy ( $\mathrm{Ex} \times \mathrm{Au}$ ) with $\mathrm{B}=.244$. Other interaction terms between professional efficacy and cynicism with autonomy (Pe/Cy x Au) or burnout dimensions with relatedness and competence (Ex/Pe/Cy x Re and Ex/Pe/Cy x Co) did 
not show any sign of significance.

From the results, it may be concluded that autonomy, relatedness, and competence of basic needs satisfaction are significant predictors for affective commitment, and autonomy as well as relatedness of basic needs satisfaction are the significant predictors for normative commitment. However, it was found that only autonomy of basic needs satisfaction showed a moderation effect on continuance commitment. This indicates that hypothesis 1 is partially supported for H11aii as only autonomy moderates the relationships between exhaustion and continuance commitment.

Based on the analysis, as the exhaustion and autonomy interaction term was the only one that showed significance, it should be reported in order to test the hypotheses and the rationalisation of the theory that was discussed in the study (Brambor, Clark, \& Golder, 2006). Also, increments of $\mathrm{R}^{2}$ is another equivalent method in testing moderation, whereby the $\mathrm{R}^{2}$ changes are significantly greater than 0 (Whisman \& McClelland, 2005) and the analysis has shown changes for $\mathrm{R}^{2}=0.045$, which indicates a moderation effect on the variables.

The results of the interaction terms are illustrated in Figure 2, which shows the interaction plot on the effect of autonomy on the relationship between exhaustion and continuance commitment. Based on the graph, the plot indicates that a high existence of exhaustion results in an elevated level of continuance commitment in the state of high autonomy. Since the results have shown that autonomy significantly predicted continuance commitment, but not exhaustion, this could explain the graph of autonomy as a conditional effect where in moderator, the effect of one predictor is conditional when the other variable is fixed at 0 (Brambor, Clark, \& Golder, 2006).

Table 1. Hierarchical multiple regression of basic needs satisfaction as a moderator between burnout dimensions and organizational commitment dimensions.

\begin{tabular}{|c|c|c|c|c|c|c|c|c|c|}
\hline \multirow[b]{2}{*}{ Variables } & \multicolumn{3}{|c|}{ Affective } & \multicolumn{3}{|c|}{ Continuance } & \multicolumn{3}{|c|}{ Normative } \\
\hline & $\begin{array}{c}\text { Step } 1 \\
\text { B }\end{array}$ & $\begin{array}{c}\text { Step } 2 \\
\text { B }\end{array}$ & $\begin{array}{c}\text { Step } 3 \\
\text { B }\end{array}$ & $\begin{array}{c}\text { Step } 1 \\
\text { B }\end{array}$ & $\begin{array}{c}\text { Step } 2 \\
\text { B }\end{array}$ & $\begin{array}{c}\text { Step } 3 \\
\text { B }\end{array}$ & $\begin{array}{c}\text { Step } 1 \\
\text { B }\end{array}$ & $\begin{array}{c}\text { Step } 2 \\
\text { B }\end{array}$ & $\begin{array}{c}\text { Step } 3 \\
\text { B }\end{array}$ \\
\hline Exhaustion & -.028 & -.013 & -.019 & .064 & .073 & .045 & .037 & .042 & .035 \\
\hline Professional Efficacy & $.224^{*}$ & .098 & .077 & -.012 & -.086 & -.11 & $.197^{*}$ & .149 & .162 \\
\hline Cynicism & $-.239 *$ & $-.2^{*}$ & $-.203^{*}$ & -.005 & .018 & .019 & $-.16^{*}$ & $-.145^{\star}$ & $-.138^{*}$ \\
\hline \multicolumn{10}{|l|}{ Moderating Variable } \\
\hline Autonomy & & $.527^{\star}$ & $.537^{*}$ & & $.31^{*}$ & $.366^{*}$ & & $.2^{*}$ & $.207^{*}$ \\
\hline \multicolumn{10}{|l|}{ Interaction Term } \\
\hline ExxAu & & & .062 & & & $.244^{*}$ & & & -.014 \\
\hline $\mathrm{Pe} \times \mathrm{Au}$ & & & -.103 & & & -.013 & & & .073 \\
\hline Cy $x \mathrm{Au}$ & & & .013 & & & -.076 & & & .074 \\
\hline $\mathrm{R}^{2}$ & .142 & .267 & .276 & .007 & .049 & .094 & .071 & .091 & .095 \\
\hline $\mathrm{R}^{2}$ Change & .142 & .125 & .009 & .007 & .042 & .045 & .071 & .02 & .004 \\
\hline $\mathrm{F}$ & $11.9^{*}$ & $19.6^{*}$ & $11.5^{\star}$ & .491 & $2.8^{*}$ & $3.1^{*}$ & $5.46^{*}$ & $5.4^{*}$ & $3.2^{*}$ \\
\hline Exhaustion & -.028 & .025 & .037 & .064 & .074 & .065 & .037 & .055 & .064 \\
\hline Professional Efficacy & $.224^{*}$ & .128 & .129 & -.012 & -.031 & -.017 & $.197^{*}$ & $.163^{*}$ & .156 \\
\hline Cynicism & $-.239 *$ & $-.168^{*}$ & $-.178^{\star}$ & -.005 & .009 & .028 & $-.16^{*}$ & $-.135^{*}$ & $-.147^{*}$ \\
\hline \multicolumn{10}{|l|}{ Moderating Variable } \\
\hline Relatedness & & $.675^{\star}$ & $.673^{*}$ & & .134 & .209 & & $.239 *$ & $.196^{\star}$ \\
\hline \multicolumn{10}{|l|}{ Interaction Term } \\
\hline Ex $x \operatorname{Re}$ & & & -.081 & & & .095 & & & -.08 \\
\hline Pex Re & & & .035 & & & .207 & & & -.1 \\
\hline Cy $x$ Re & & & .093 & & & -.025 & & & .01 \\
\hline $\mathrm{R}^{2}$ & .142 & .327 & .332 & .007 & .014 & .034 & .071 & .097 & .106 \\
\hline $\mathrm{R}^{2}$ Change & .142 & .185 & .006 & .007 & .007 & .02 & .071 & .026 & .009 \\
\hline $\mathrm{F}$ & $11.9^{*}$ & $26.1^{*}$ & $15.1^{*}$ & .491 & .75 & 1.08 & $5.46^{*}$ & $5.75^{*}$ & $3.57^{*}$ \\
\hline Exhaustion & $\begin{array}{l}.028 \\
-.028 x-y\end{array}$ & -.036 & $\begin{array}{l}.044 \\
\end{array}$ & .064 & 0.063 & .061 & .037 & .036 & .048 \\
\hline Professional Efficacy & $.224^{\star}$ & .082 & .073 & -.012 & -.021 & -.011 & $.197^{*}$ & $.189^{*}$ & $.195^{\star}$ \\
\hline Cynicism & $-.239 *$ & -.089 & -.083 & -.005 & .004 & .019 & $-.16^{*}$ & $-.151^{*}$ & $-.162^{*}$ \\
\hline \multicolumn{10}{|l|}{ Moderating Variable } \\
\hline Competence & & $.635^{\star}$ & $.643^{*}$ & & .038 & .069 & & .037 & .018 \\
\hline \multicolumn{10}{|l|}{ Interaction Term } \\
\hline $\mathrm{Ex} \times \mathrm{Co}_{0}$ & & & .044 & & & -.054 & & & -.051 \\
\hline $\mathrm{Pe} \times \mathrm{Co}$ & & & -.059 & & & .167 & & & .018 \\
\hline $\mathrm{Cy} \times \mathrm{Co}$ & & & .006 & & & .128 & & & -.021 \\
\hline $\mathrm{R}^{2}$ & .142 & .383 & .387 & .007 & .008 & .029 & .071 & .071 & .078 \\
\hline $\mathrm{R}^{2}$ Change & .142 & .241 & .005 & .007 & .001 & .021 & .071 & .000 & .008 \\
\hline $\mathrm{F}$ & $11.9^{*}$ & $33.3^{*}$ & $19.2^{*}$ & .491 & .411 & .905 & $5.46^{*}$ & $4.14^{*}$ & $2.56^{\star}$ \\
\hline
\end{tabular}

* Significant at 0.05 level

Ex=Exhaustion, Pe=Professional efficacy, $\mathrm{Cy}=$ Cynicism Au=Autonomy Re=Relatedness $\mathrm{Co}=$ Competence 


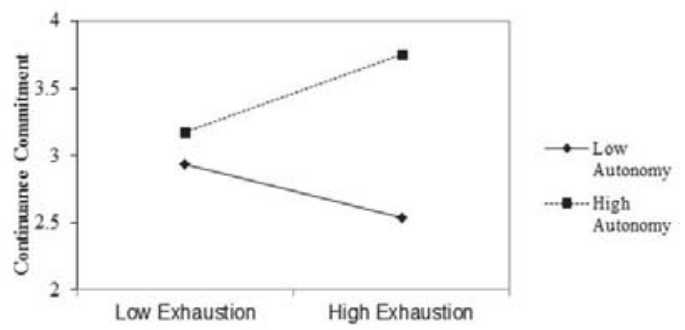

Figure 2. Interaction plot of effect of autonomy on the relationship between exhaustion and continuance commitment

The results for hypothesis 2, which was to examine the moderation effect of basic needs satisfaction on work-family conflict and organizational commitment, is shown in Table 2. Based on the affective commitment column, it was found that although the final model was significant with the addition of interaction terms between burnout dimensions with autonomy $\left(R^{2}=.239, F(5,214)=12.4, p<.05\right)$, relatedness $\left(R^{2}=.292, F(5,214)=17.7, p<.05\right)$ and competence $\left(R^{2}=.382\right.$, $F(5,214)=26.4, p<.05)$, the interaction terms were not significant. This indicates that autonomy, relatedness, and competence of basic needs satisfaction did not moderate the relationships between WIF and FIW of work family conflict and affective commitment.

The results of the normative organizational commitment column found that the additions of autonomy and relatedness in the final model with the added interaction terms were also significant with $R^{2}=.056, F(5,214)=2.55, p<.05$ and $R^{2}=.067, F(5,214)=3.06, p<.05$. However, the results showed that the addition of competence as the moderating variable did not reach statistical significance with $R^{2}=.027, F(3,216)=1.99, p>.05$ and interaction term $R^{2}=.037$, $F(5,214)=1.65, p>05$. Based on these results, since all of the interaction terms were not significant, this indicates that autonomy, relatedness, and competence do not moderate the relationships between WIF and FIW of work-family conflict with normative commitment.

Similar results appeared on the final model of continuance commitment where significance was reached after the addition of the interaction terms between burnout dimensions with autonomy $\left(R^{2}=.084, F(5,214)=3.91, p<.05\right)$, relatedness $\left(R^{2}=.076, F(5,214)=3.5, p<.05\right)$ and competence $\left(R^{2}=.054, F(5,214)=2.44, p<.05\right)$. However, only the interaction term of WIF and relatedness (WIF $x$ Re) was significant at $B=.292$ while the rest of the interaction terms did not show any sign of statistical significance. This suggests that relatedness of basic needs satisfaction is the only factor that moderates the relationships between WIF and continuance commitment.

Based on the results of the analysis, only the WIF and relatedness interaction term reached a significant level. This indicates that hypothesis 2 is partially supported (H22aii) in terms of the moderation effect between burnout and organizational commitment. In order to illustrate the results of the interaction terms, Figure 3 outlines the interaction plot on the effect of relatedness on the relationship between WIF and continuance commitment. Based on the graph, the plot shows that as WIF increases, continuance commitment will increase when there is a high level of relatedness. This indicates that relatedness will moderate the effect of WIF on continuance commitment, as the commitment will continue emerging, although one has to deal with WIF in work family conflict.

Table 2. Hierarchical multiple regression of basic needs satisfaction as a moderator between work family conflict dimensions and organizational commitment dimensions

\begin{tabular}{|c|c|c|c|c|c|c|c|c|c|}
\hline \multirow[b]{2}{*}{ Variables } & \multicolumn{3}{|c|}{ Affective } & \multicolumn{3}{|c|}{ Continuance } & \multicolumn{3}{|c|}{ Normative } \\
\hline & $\begin{array}{c}\text { Step } 1 \\
\text { B }\end{array}$ & $\begin{array}{c}\text { Step } 2 \\
\text { B }\end{array}$ & $\begin{array}{c}\text { Step } 3 \\
\text { B }\end{array}$ & $\begin{array}{l}\text { Step } 1 \\
\text { B }\end{array}$ & $\begin{array}{c}\text { Step } 2 \\
\text { B }\end{array}$ & $\begin{array}{c}\text { Step } 3 \\
\text { B }\end{array}$ & $\begin{array}{c}\text { Step } 1 \\
\text { B }\end{array}$ & $\begin{array}{c}\text { Step } 2 \\
\text { B }\end{array}$ & $\begin{array}{c}\text { Step } 3 \\
\text { B }\end{array}$ \\
\hline WIF & -.048 & -.045 & -.045 & -.138 & -.136 & -.137 & -.077 & -.075 & -.074 \\
\hline FIW & -.16 & -.134 & -.15 & $.287^{*}$ & $.299^{*}$ & $.283^{\star}$ & .059 & .071 & .064 \\
\hline $\begin{array}{l}\text { Moderating } \\
\text { Autonomy }\end{array}$ & & $.606^{*}$ & $.613^{*}$ & & $.279 *$ & $.289 *$ & & $.285^{*}$ & $.282^{*}$ \\
\hline Interaction T & & & & & & & & & \\
\hline WIF x Au & & & .062 & & & -.059 & & & -.135 \\
\hline FIW $\times A u$ & & & -.103 & & & .137 & & & .148 \\
\hline $\mathrm{R}^{2}$ & .047 & .231 & .239 & .04 & .078 & .084 & .003 & .05 & .056 \\
\hline $\mathrm{R}^{2}$ Change & .047 & .185 & .007 & .04 & .038 & .005 & .003 & .046 & .007 \\
\hline $\mathrm{F}$ & $5.32^{*}$ & $21.7^{*}$ & $12.4^{*}$ & $4.55^{\star}$ & $6.13^{*}$ & $3.91^{*}$ & .38 & $3.76^{\star}$ & $2.55^{*}$ \\
\hline$\overline{\text { WIF }}$ & $\begin{array}{c}.048 \\
\end{array}$ & -.051 & -.042 & - -.138 & -.138 & "-.176 & "-.077 & "-.078 & -.098 \\
\hline FIW & -.16 & -.01 & -.024 & $.287^{*}$ & $.323^{*}$ & $.361^{*}$ & .059 & .128 & .148 \\
\hline
\end{tabular}




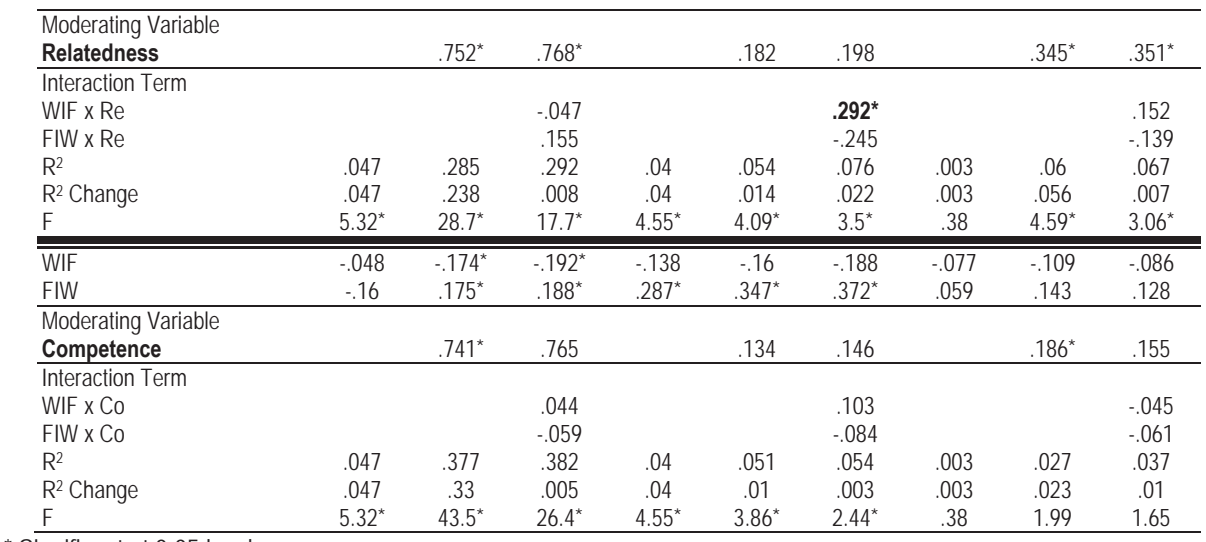

* Significant at 0.05 level

WIF=Work Interfering with Family, FIW=Family Interfering with Work, Au=Autonomy,Re=Relatedness, Co=Competence

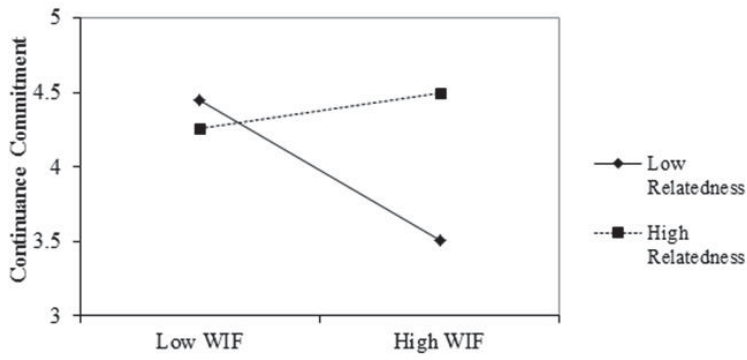

Figure 3. Interaction plot of the effect of relatedness on the relationship between WIF and continuance commitment

\section{Discussion and Conclusion}

The focus of this study was to investigate the effects of the basic needs satisfaction dimensions (autonomy, competence and relatedness) as the moderating factor between burnout (exhaustion, professional efficacy and cynicism), work-family conflict (work interfering with family (WIF) and family interfering with work (FIW)), and organizational commitment (affective, continuance and normative).

The results on moderation using hierarchical regression analysis found that autonomy moderates the relationships between exhaustion and continuance commitment, while relatedness moderates the relationships between WIF and continuance commitment. As for the purpose of this study, it was found that only autonomy and relatedness acted as a moderator compared to previous research that found all three basic psychological needs (autonomy, competence and relatedness) moderating the relationships between subjective norms and intention (Harris \& Hagger, 2007). On the other hand, other researchers specifically used different instruments of motivation, such as self-determination in work motivation (Fernet, Guay, \& Seneccal, 2004), job resources (Faisal, Rosman, \& Anwar, 2014), and work motivation (Fernet, Gagne, \& Austin, 2010).

The finding that autonomy moderates the relationships between exhaustion and continuance commitment had similar results in Plana, Fabregat, and Gassio (2003) who found that rather than trying to escape from exhaustion, it was more rewarding to utilize individual resources and skills in order to boost personal or organizational accomplishments such as autonomy. When employees' needs at work are satisfied, they become more committed to the organization and improve in productivity (Akinyele, 2007; Bakker, Demerouti, Boer, \& Schaufeli, 2003). According to Nasrin's (2010) findings, need satisfaction at work is related to work motivation and job performance; thus, autonomy is needed to support their effort to promote positive-work-related outcomes.

Concerning the finding that relatedness moderates the relationship between WIF and continuance commitment, it was found in a study by Glebocka and Losowska (2007) that families, power, and prestige are the most important 
resources, while Bakker, Demerouti, Boer and Schaufeli (2003) state that social support is strongly correlated with relatedness satisfaction. Social support from team members or quality relationships and job characteristics were the motivation factors for employees to continue working with the organization while remaining committed (Norzihan, Ferlis, \& Beddu, 2008; Fernet, Gagne, \& Austin, 2010).

The framework of the COR theory model can provide understanding of a situation where autonomy, exhaustion and continuance commitment occur. Work demands can lead to exhaustion (as it was a predictor of burnout), while commitment may be predicted from job resources (Bakker, Demerouti, Boer, \& Schaufeli, 2003). The presence of exhaustion in the process of work demands leads to loss in resources. The lost resources need to be replaced by other available resources in order to prevent further loss. The continuance commitment, which should be nurtured during employment, could be used as an available resource to induce exhaustion. However, this depends on the degree of continuance commitment. For example, if the skill/knowledge invested in the organization does not help to manage exhaustion wisely, this could lead to further setbacks. At this point, the function of the autonomy motivation factor, such as having the power in decision-making, may be utilized in the investment of resources to adapt to a resource loss situation. Having a say in work such as the authority to delegate tasks to subordinates may reduce exhaustion and help to prevent continuance commitment from being diminished.

As for relatedness, it was found to moderate the relationships between WIF and continuance commitment. This is in accordance with COR theory as when there is conflict in balancing between work and family life, it triggers a loss in resources, as it is doubtful that employees can perform the job successfully (Grandey \& Cropanzano, 1999). This includes extensive working hours that result in employees spending more time at work rather than at home. The sacrifices of time spent on juggling work and family matters could affect continuance commitment if the employee feels that leaving the organization will be of greater benefit, specifically the assurance of more family hours. However, when the relatedness functions as a motivation factor - such as having supportive team members who take turns to work extra hours - this can reduce the conflict of WIF and maintain or reduce the loss of continuance commitment.

There are several limitations of this study which need to be explored in the future. Firstly, this study only focuses on one group category, which is the administrative/professional group in a public sector setting. Thus, the findings cannot be generalised to other work categories or sectors that do not deal with providing and delivering services to the public. This study did not explore the potential causes or factors of burnout and work-family conflicts faced by the respondents.

For future research purposes, investigation on the cause of burnout and work-family conflict is needed to understand the environment that could lead to intensification of stressors. It would be advantageous to study other potential stress factors at the work place, as there are many potential stressors in the work environment that could affect employees' commitment towards their organization. It is also suggested that respondents from other work groups be incorporated, such as support groups or private based companies, since they have different work tasks and environments.

Basic needs satisfaction at work is a vital motivation factor in obtaining high commitment from the employees, which may be evidenced by their performance. It can also heighten employees' commitment towards their organizations since needs satisfaction is an innate motivation that can affect optimal psychological functioning and determination at work. However, employees are vulnerable to obstacles and stressors at the workplace caused by burnout and conflicts in balancing between work and family life. For those reasons and in line with the purpose of this study, it is important to acknowledge the capacity of basic needs satisfaction at work, as it has been proven to have an effect on organizational commitment, despite the strain of burnout and work-family conflict issues.

\section{References}

Aamodt, M .G. (2010). Industrial/organizational psychology: An applied approach. (6th ed). USA : Wadsworth Cengage Learning.

Akintayo, D. I. (2010). Work-family role conflict and organizational commitment among industrial workers in Nigeria, Journal of Psychology and Counselling, 2 (1), 1-8.

Akinyele, S. T. (2007). Needs satisfaction: An effective tool for workers commitment to work. Research Journal of Business Management. 1, 72-79.

Bakker, A. B., Demerouti, E., Boer, E. D. \& Schaufeli, W. B. (2003). Job demands and job resources as predictors of absence duration and frequency. Journal of Vocational Behavior, 63, 341-356.

Brambor, T., Clark, W. R. \& Golder, M. (2006). Understanding interaction models: Improving empirical analyses. Political Analysis, 14, 63-82.

Brehm, J., \& Gates, S. (1997). Working, shirking, and sabotage: Bureaucratic responses to a democratic public. Ann Arbor: University of Michigan Press.

Broeck, A. V, Vansteenkiste, M., Witte, H. D., Soenens, B. \& Lens, W. (2010). Capturing autonomy, competence and relatedness at 
work: Construction and initial validation of the work-related basic need satisfaction scale. Journal of Occupational and Organizational Psychology, 83, 981-1002.

Carlson, D. S., Karmac, K. M. \& Williams, L. J. (2000). Construction and initial validation of a multidimensional measure of work-family conflict. Journal of Vocational Behaviour, 56, 249-276.

Choong, Yuen-Onn, Wong, Kee-Luen \& Lau, Teck-Chai (2011), Intrinsic motivation and organizational commitment in Malaysian private higher education institutions: An empirical study. Journal of Arts, Science and Commerce, 2 (4), 40-50.

Deci, E. L., Ryan, R. M., Gagné, M., Leone, D. R., Usunov, J., \& Kornazheva, B. P. (2001). Need satisfaction, motivation, and well-being in the work organizations of a former Eastern bloc country. Personality and Social Psychology Bulletin, 27, 930-942.

Deci, E. L. \& Ryan, R. M. (2000). The 'what' and 'why' of goal pursuits: Human needs and the self-determination of behavior. Psychology Inquiry, 11 (4) 222-268.

Fernet, C., Gagne, M. \& Austin, S. (2010), When does quality of relationships with coworkers predict burnout over time? The moderating role of work motivation. Journal Of Organizational Behaviour, 1163-1180.

Fernet, C., Guay, F. \& Senecal, C. (2004). Adjusting to job demands: The role of work self-determination and job control in predicting burnout. Journal of Vocational Behavior, 65, 39-56.

Faisal, K., Rosman, M. D. Y, \& Anwar, K. (2014). Job demands, burnout and resources in teaching a conceptual review. World Applied Sciences Journal, 30 (1), 20-28.

Frank S. A \& Lewis G. B (2003). Government employees: Working hard or hardly working? American Review of Public Administration, 34 (1), 36-51.

Gagne, M. \& Deci, E. L. (2005). Self-determination theory and work motivation. Journal of Organizational Behaviour, 26, $331-362$.

Gemlik, N, Sisman, F. A \& Sigri, U. (2010). The relationship between burnout and organizational commitment among health sector staff in Turkey. Journal of Global Strategic Management, 8, 137-149.

Glebocka, A. \& Lisowska, E. (2007). Professional burnout and stress among Polish physicians explained by the Hobfoll Resources Theory. Journal of Physiology and Pharmacology, 8 (5), 243-252.

Gorgierski M. J. \& Hobfoll S. E. (2008). Work can burn us out or fire us up: Conservation of resources in burnout and management. Canada: Nova Science Publishers Inc.

Grandey, A. A. \& Cropanzano, R. (1999). The conservation of resources model applied to work-family conflict and strain. Journal of Vocational Behavior, 54, 350-370.

Greenhaus, J., \& Beutell, N. (1985). Sources of conflict between work and family roles. Academy of Management Reviews, 10 (1), $76-$ 88.

Harris, J. \& Hagger, M. S. (2007). Do basic psychology needs moderates relationships within the Theory of Planned Behavior? Journal of Applied Biobehavioral Research, 12, 1, 43-64.

Hobfoll S. E. \& Freedy J. (1993). Conservation of resources: A general stress theory applied to burnout. In Schaufeli W. B., Maslach C., Marek T. (Eds.). Professional burnout: Recent developments in theory and research, (pp. 115-129). Washington, DC: Taylor \& Francis.

Hobfoll S. E. (2001). The influence of culture, community, and the nested self in the stress process: Advancing conservation of resources theory. Applied Psychology: An International Review, 50, 337-370

Hobfoll S. E. (2011). Conservation of resources caravans in engaged settings. Journal of Occupational and Organizational Psychology, 84, 116-122.

Hobfoll S.E. (1989). Conservation of resources: A new attempt at conceptualizing stress. American Psychologist, 44 (3), $513-524$.

Hodgins, H, S. \& Knee, R. (2004). The integrating self and conscious experience. Handbook of self-determination research. USA: University of Rochester Press.

Ishak Mad Shah (2004). Pengenalan Psikologi Industri dan Organisasi (Introduction to Industrial and Organizational Psychology). Johor Bahru: Universiti Teknologi Malaysia.

Jackson, S. E., Turner, J. A. \& Brief, A. P. (1987). Correlates of burnout among public service lawyers. Working Paper Series, Center for Research on Information Systems. New York University.

Jawahar, I. M., Stone, T. H. \& Kisamore, J. L. (2007). Role conflict and burnout: The direct and moderating effects of political skill and perceived effects of political skill and perceived organizational support on burnout dimensions. International Journals of Stress Management, 14 (2), 142-159.

Krejcie, R., \& Morgan, D. (1970). Determining sample size for research activities. Educational and Psychological Measurement, 30, 607610.

Kuvaas, A. (2009). A test of hypotheses derived from self-determination theory among public sector employees. Employee Relations, 31 (1), 39-56.

Lam, C. F. \& Gurland, S. T. (2008). Self-determined work motivation predicts job outcomes but what predicts self-determined work motivation? Journal of Research in Personality, 42, 1109-1115.

Marescaux, E., Winne, S. D. \& Sels, L. HRM practices and work outcomes: The role Of basic need satisfaction.[Online] Available: https://lirias.kuleuven.be/bitstream (December 15, 2011).

Maqsood Ahmed, Muhammad Muddasar \& Saleem Perviaz (2012). The impact of work-family conflict and pay on employee job satisfaction with the moderating effect of perceived supervisor support in Pakistan banking sector. Global Journal of Management and Business Research, 12 (6), 276-285.

Maslach, C. (1982). Understanding burnout: Definitional issues in analyzing a complex phenomenon. In W. S. Paine (Ed.), Job stress 
and burnout (pp. 29-40). Beverly Hills, CA: Sage.

Maslach, C., Jackson, S. E., Leiter, M. P., Schaufeli, W. B. \& Schwab, R. (1986). Maslach Burnout Inventory. Third Edition.Mind Garden Inc.

McPadden, K. (2006). Conservation of resources theory. [Online] Available: http://wfinework.bc.edu/encylopedia, (October 18, 2011).

Meyer, J. P. \& Allen, N. J. (1991). A three-component conceptualization of organizational commitment. Human Resource Management Review, 1 (1), 61-89.

Molix, L. A. \& Nichols, C .P. (2013). Satisfaction of basic psychological needs as A mediator of the relationship between community esteem and well-being. International Journal of Well-Being, 3 (1), 20-34.

Muhyiddin Yassin. (2010). Embracing the New Economic Model: Public-private sector and people synergy. Fifteenth Civil Service Conference Speech. Kuala Lumpur.

Najihah Hanisah, M., Norsyamina, Z., Mizan, H. \& Jeniwaty, M. J. (2011). Organizational commitment and job burnout among employees in Malaysia. International Conference on Business and Economics Research, Vol.1, IACSIT, Kuala Lumpur.

Nasrin Arshadi (2010). Basic need satisfaction, work motivation and job performance in an industrial company in Iran, Procedia Social and Behavioural Science, 5, 1267-1272.

Neubert, M. J. \& Wu, C. (2009). Actions commitments. In Klein, H .J., Becker, T. E. \& Meyer, J. P. Commitment in Organizations, Accumulated Wisdoms and New Directions (pp. 419-452). New York: Routledge.

Perry, J. L. \& Wise, L. R.(1990). The motivational bases of public service. Public Administration Review, 50 (3), 367-373.

Plana, A. B., Fabregat, A. A. \& Gassio, J. B. (2003). Burnout syndrome and coping strategies: A structural relations model. Psychology in Spain, 7 (1), 46-55.

Ryan, R. M. \& Deci, E. L. (2004). An overview of self-determination theory: An organismic-dialectical perspective in handbook of selfdetermination research. Rochester: University of Rochester Press.

Salanova, M., Bakker, A. B. \& Llorens, S. (2006). Flow at work: Evidence for an upward spiral of personal and organizational resources, Journal of Happiness Studies, 7, 1-22.

Senecal C., Vallerand R. J. \& Guay F. (2001). Antecedents and outcomes of work-family conflict: Toward a motivational model. Society for personality and Social Psychology, 27 (2), 176-186.

Sheldon, K. M. \& Bettencourt, B. A. (2002). Psychological need satisfaction and subjective well-being within social groups. British Journal of Social Psychology, 41, 25-38.

Schaufeli, W. B., van Dierendonck, D. and van Gorp, K. (1996) Burnout and reciprocity: towards a dual-level social exchange model. Work and Stress, 10, 225- 237.

Schultz, D. \& Schultz, S. E. (2014), Psychology and work today. London: Pearson Education Ltd.

Siegel, P. A, Post, C., Fishman, A. Y., Brockner, J. \& Garden, C. (2005). The moderating influence of procedural fairness on the relationship between work-life conflict and organizational commitment. Journal of Applied Psychology, 90 (1), 13-24.

Silman F. (2014). Work-related basic need satisfaction as a prediction of work engagement among academic staff in Turkey. South African Journal of Education, 34 (3), 156-169.

Vallerand, R. J. \& Ratelle, C. F. (2004). Intrinsic and extrinsic motivation: A hierarchical model Handbook of self-determination research. Rochester: University of Rochester Press.

Whisman, M. A. \& McClelland, G. H. (2005). Designing, testing and interpreting interactions and moderator effects in family research. Journal of Family Psychology, 19 (1), 111-120.

Wright, T. A. (2004). Commitment, psychological well-being and job performance: An examination of Conservation of Resources Theory and job burnout. Journal of Business and Management, 11, 234-245. 